\title{
Recurrent Adult Spinal Cord Neoplasm
}

National Cancer Institute

\section{Source}

National Cancer Institute. Recurrent Adult Spinal Cord Neoplasm. NCI Thesaurus. Code C71713.

The reemergence of a spinal cord neoplasm in adulthood after a period of remission. 